\title{
FILOSOFÍA DE SENTIDO COMÚN
}

\author{
Common Sense PhiLosophy
}

\author{
Alejandro Tomasini Bassols \\ DOI: 10.26754/ojs_arif/arif.202115389
}

\begin{abstract}
Javier Vilanova Arias (2021), Filosofía de Sentido Común. Madrid: Guillermo Escolar Editor, 2021.
\end{abstract}

El libro de Javier Vilanova, Filosofía de Sentido Común, combina al menos una virtud evidente y una falla notoria, características que no siempre es fácil conjugar: se trata de un libro que, por una parte, hace pensar pero que, por la otra, no resulta convincente. Paralelamente, algo parecido sucede con el estilo en el que está redactado el texto: por una parte, se trata de un estilo literario tremendamente original, yo diría inclusive sui generis, pero por la otra no estoy seguro de que la forma por la que el autor opta para presentar su pensamiento no le resulte a más de uno un tanto desconcertante, por no decir inclusive irritante. En lo que sigue, hago una presentación sintética del contenido del libro para posteriormente considerar más en detalle un par de facetas de la posición general que el autor defiende.

El tema del libro de Vilanova es el sentido común, un tema que cualquier persona interesada en filosofía de inmediato sentiría como un platillo de gastronomía filosófica de muy alta calidad. El libro tiene dos partes, "Filosofía desde el sentido común” y "Filosofía sobre el sentido común”, siendo con mucha la segunda la parte filosóficamente más interesante del texto. Salta de inmediato a la vista el hecho de que el autor parece haber hecho un gran esfuerzo para adaptar su forma de redactar a su tema general. A todas luces, él aspira a expresarse de modo natural, espontáneo, "común", sólo que el resultado no es del todo afortunado. Esto es a la vez interesante e importante, porque apunta a lo que en mi opinión es una cierta incomprensión por parte del autor de su tema central, esto es, el sentido común. Preguntémonos primero: ¿cuál es la peculiaridad literaria de Vilanova? Éste obviamente aspira a expresarse sin tecnicismos, de manera natural, espontánea y fluida, evitando las frases rimbombantes, las formulaciones 
rebuscadas y pretenciosas y más en general todo aquello que a menudo hace del lenguaje de los filósofos un lenguaje oscuro y hasta incomprensible. El problema es que Vilanova entiende el contraste entre lenguaje filosófico técnico y el lenguaje del sentido común como un contraste entre lenguaje técnico y lenguaje mundano, pedestre y casi corriente, lo cual tiene el efecto de quitarle seriedad a su discurso. En otras palabras, da la impresión de que Vilanova piensa que la forma apropiada para neutralizar la pesantez temática en la que en ocasiones se incurre en filosofía consiste en expresarse a la ligera, incrustando a derecha e izquierda comentarios (en ocasiones, casi impertinentes) a lo largo y ancho de su exposición como si estuviera alegremente departiendo y divagando con amigos en el bar de la esquina. Para dejar en claro que no estoy distorsionando los hechos, permítaseme dar unos cuantos ejemplos. Dice Vilanova:

1) "Déjenme primero dar un suspiro ("uff ... vaya preguntita")" (p. 36).

2) "Como dijo el viejo Aristóteles (un tipo listo donde los haya) ..." (p. 27).

3) "... ocurre que alguien decide recusar toda la tradición e iniciar algo nuevo y revolucionario (iViva Zapata!)” (p. 62)

4) "Vale, pero si ahora viene el torpe de turno y recuerda mal la hora o la distancia, o se olvida de apretar un tornillo, todo nuestro método y nuestra certeza se van a la porra." (p. 78)

5) "Una facción defiende que el género viene determinado biológicamente y que es "contra natura" (iMoore se habría alegrado de que se lo pusieran tan fácil!) intentar alterarlo artificialmente." (p. 98).

Esa no es la forma estándar de redactar un texto filosófico. Ahora bien, ¿por qué doy estoy ejemplos, tomados todos ellos al azar? Porque me parece que revelan una cierta incomprensión filosófica consistente en asociar el enfoque del sentido común con la bonhomía, con el rechazo de toda clase de rigor y de reglamentación, con la fácil y engañosa actitud de "laisser faire, laisser passer" y con el lenguaje del camarero o del taxista. Comentarios así inundan sobre todo la primera parte del texto e inevitablemente le imprimen un tono excesivamente coloquial al libro. Aquí hay que tener cuidado para no confundirnos: desde luego que nos habrían embargado la admiración y el respeto si Vilanova hubiera escrito un diálogo como los de Platón, fundiendo así lenguaje coloquial con belleza y con profundidad filosófica, pero lo que él logra es más bien degradar la discusión filosófica misma a través de un discurso que es de redacción fácil y que proyecta la idea de que en el fondo la discusión filosófica convencional se puede llevar a cabo sin definiciones, sin terminología ad hoc, sin precisiones argumentativas, etc. O sea, 
desde las primeras páginas el sentido común queda, por así decirlo, configurado como si fuera algo que la filosofía tradicional vino a suplantar y para lo cual ésta alteró el modo amigable, bonachón, etc., de expresarnos, por uno seco, árido, sin vida. Vilanova estaría entonces desenmascarando a la usurpadora, esto es, a la filosofía, a través de la recuperación del lenguaje realmente apropiado para las controversias filosóficas, esto es, el lenguaje de la calle. Debo decir que soy de la opinión de que Vilanova comete en este punto un error categorial. Antes de criticarlo, sin embargo, veamos rápidamente qué es lo que sostiene.

Hay un par de ideas que operan como columna vertebral de la primera parte del libro, Una de ellas parecería ser la de que los problemas filosóficos se pueden plantear en el lenguaje vernáculo y que son tan aprehensibles o inteligibles como cuando se les formula en contextos de filosofía académica, pero ésta traería aparejada otra idea importante, a saber, que es sólo cuando son planteados en términos del lenguaje oral, cotidiano, libre, etc., que a los problemas filosóficos se les puede encontrar una salida intelectualmente satisfactoria. Pienso que Vilanova está equivocado en este punto, en parte porque su posición es en última instancia incoherente. Si Vilanova hubiera hecho suya la tesis de que los enredos conceptuales surgen cuando el lenguaje es empleado filosóficamente, entonces su opción por el lenguaje coloquial habría sido muy atinada, pero entonces él habría tenido que convencernos de que los problemas filosóficos (o por lo menos los que él pasa en revista) dejarían de plantearse tan pronto cambiáramos nuestra forma de expresarnos. Pero no es eso lo que Vilanova hace: él sigue considerando que los problemas filosóficos son genuinos problemas y lo que al respecto sostiene es simplemente que es más fácil que éstos reciban una respuesta satisfactoria si se les trata de manera laxa, en un lenguaje de todos los días y, claro está, desde la perspectiva del sentido común. Confieso que no puedo menos que pensar que la apuesta de Vilanova está destinada al fracaso. Intentaré hacer ver que ello es así considerando un caso concreto de discusión.

El primer capítulo del libro está consagrado al tema filosófico clásico del conflicto entre la libertad de la voluntad y el determinismo aunque, como era de esperarse, Vilanova no presenta el problema en sus términos clásicos. Aplicando su estrategia de sustitución de una forma de expresarse por otra, él más bien pregunta: ¿quién toma mis decisiones? Así planteado el problema, de inmediato nos percatamos de que se produjo un cambio temático y de que ya no nos las estamos viendo con el problema filosófico tradicional, el cual no tiene que ver con la cuestión de si otros toman decisiones por mí sino con la cuestión de si eso que yo tomo como decisión mía es efectivamente el producto de un acto 
mío de voluntad y no de un acto provocado por factores causales externos a mí. Dejando de lado este detalle, el problema en manos de Vilanova se transforma en un primer momento en el conflicto "nature/nurture", esto es, a grandes rasgos el conflicto entre naturaleza y cultura. Dado que es imposible mostrar que al momento de tomar decisiones sólo el equipo biológico cuenta o que sólo vale la educación que asimilamos y en general la cultura en la que crecimos, Vilanova sin titubear propone una solución "de sentido común", la cual consiste en resaltar la importancia y la presencia de un tercer factor. Dice:

Pues bien, en mi opinión hay que añadir una "tercera naturaleza" en el ser humano, no menor ni menos relevante que las otras dos, aunque sea muchas veces olvidada. Mi tesis es que el ser humano tiene una tercera naturaleza, y esa naturaleza es "ser persona". O mejor: "ser una persona". (p. 29).

Para empezar, nótese que si ser humano y ser una persona son básicamente lo mismo, lo que Vilanova con tanto entusiasmo sostiene es que todo ser humano es un ser humano (o toda persona una persona). Es difícil percibir qué avance se logra con trivialidades de esa índole. En todo caso, de acuerdo con él, esta "tercera naturaleza" es el elemento crucial para superar el conflicto "naturaleza/cultura". Lo que entonces ahora tenemos que preguntarnos es: ¿qué es una persona?

A diferencia de lo que proponía, por ejemplo, P. Strawson, para quien una persona es un ser al cual podemos adscribirle tanto propiedades físicas como propiedades mentales (usando 'mentales' en el sentido filosófico estándar), para Vilanova una persona es algo que es un ser de nuestra especie cuya identidad se va construyendo a lo largo de su vida, pues resulta de la totalidad de sus experiencias y de las consecuencias de sus experiencias y decisiones, las cuales no son predecibles o no lo son siempre. Inclusive si somos las más monótonas de las personas, nuestra monotonía es el resultado de nuestras decisiones y ello es parte de nuestra biografía. En palabras de Vilanova:

Incluso aquel que cada día de su vida ha hecho exactamente lo mismo, elegido exactamente lo mismo en el menú, tomando exactamente las mismas decisiones, lo ha hecho porque cada día ha decidido hacerlo (p. 30).

La ventaja del enfoque de Vilanova consistiría al parecer en que con él se supera tanto el determinismo biológico como el social y al ser humano se le devuelve su facultad de elegir libremente, de decidir por cuenta propia. Ahora estamos en posición de re-describir los hechos y hacer ver que el problema de la determinación de la voluntad era en efecto un pseudo-problema. Una persona actúa libremente porque tanto su composición natural como su constitución 
cultural son de ella. Vilanova completa su respuesta con una teoría de deseos, intenciones y demás ítems mentales de segundo orden. Así, no sólo deseamos sino que a menudo deseamos tener precisamente los deseos que tenemos y no otros. Somos, pues, autónomos o libres cuando nuestros deseos, intenciones, voliciones y demás de segundo orden son congruentes o coinciden con los de primer orden, es decir, no se da el caso de que uno quiera algo y luego se arrepienta de eso que quería. Cito a Vilanova:

En consecuencia, somos o al menos nos sentimos autónomos, nos sentimos dueños de nosotros mismos, sentimos que "estamos al mando", que "tenemos el poder" de nuestras vidas, nos sentimos, en definitiva, libres cuando nuestros deseos son los que deseamos tener, nuestras preferencias son las que preferíamos tener, y cuando nuestra voluntad se guía por aquellos criterios que nuestra voluntad elige como los mejores. (p. 36).

Pero ¿cómo se accede a tan envidiable estado? Vilanova reconoce que no lo sabe, pero de lo que está seguro es de que es tomando "decisiones existenciales", generando hábitos apropiados y ponderando nuestras decisiones como se logra ser libre. Difícilmente podría estarse en desacuerdo con Vilanova salvo en un punto: que eso sea una solución al problema de la determinación de la voluntad y del libre albedrío.

No voy a analizar en todo detalle la posición de Vilanova. Me limitaré a señalar lo que en mi opinión son algunas deficiencias en su razonamiento, pero lo que más me interesa hacer es tratar de diagnosticar el error profundo de todo su planteamiento.

La primera objeción que se puede elevar en contra de Vilanova es que parte de su "solución" es una magnífica petición de principio! Si aceptamos (con él) que cada día la persona hace "lo que decide hacer": ¿en dónde está entonces el problema de la determinación de la voluntad? El problema queda automáticamente resuelto, puesto que se admite de entrada que cada día el individuo decide qué quiere hacer. En segundo lugar, la jerarquía de estados mentales es irrelevante. El que yo desee no haber deseado algo no hace que la acción que se deriva de mi deseo haya sido una acción causada y, por lo tanto, no libre. La acción que se deriva de un deseo genuino automáticamente es libre, independientemente de si a su vez el deseo fue causado o no, puesto que la persona habrá actuado como de hecho quería hacerlo, inclusive si posteriormente repudia su acción, es decir, se arrepiente de haber deseado lo que de hecho deseó. En tercer lugar, vale la pena señalar que toda la parafernalia de estados mentales que Vilanova requiere para reforzar su teoría de que a pesar de la naturaleza y la cultura somos seres libres 
es lo más contrario que podría haber a una visión de sentido común. De seguro que si hablamos de intenciones de segundo grado tendremos derecho a hablar de intenciones de tercer grado, de cuarto grado, etc., pero ¿es una concepción así congruente con el sentido común? Lo dudo. Ahora bien, si estoy en lo correcto, entonces el replanteamiento de los problemas filosóficos para supuestamente ser tratados desde la plataforma del sentido común, ilustrado en el ejemplo del conflicto entre libertad y determinismo, queda exhibido como un programa fallido. Espero completar este diagnóstico con un veloz examen de la segunda parte del libro.

Temáticamente, sin duda la segunda parte del libro, "Filosofía sobre el sentido común", es con mucho la más interesante. Es difícil, sin embargo, no sentir que Vilanova falla rotundamente en articular una concepción coherente y genuinamente elucidatoria del sentido común. Ciertamente, él realiza una interesante investigación de dicha noción, pero al carecer de un método y por no haber establecido previamente ciertas conexiones importantes como la relación entre el sentido común y el lenguaje natural o la relación entre el sentido común y lo que en algún momento B. Russell llamó 'creencias instintivas', sus resultados sólo pueden ser caóticos. Vilanova pregunta por lo que el sentido común es, por sus rasgos centrales, por sus relaciones con diversas disciplinas, como la lógica y la psicología, por su origen y su estructura así como por sus relaciones con la filosofía $y$, aunque de manera un tanto desperdigada, dice bastantes cosas interesantes sobre el tema, pero lo cierto es que no logra cerrar su investigación de manera exitosa. Por ejemplo, sobre el sentido común nos dice, inter alia, que es básico, legitimador de creencias, asistemático, explicativo, motivo y causa de acciones, sirve para persuadir, admite grados, es tácito, cotidiano y práctico. Todo esto y más puede ser cierto, pero ¿de qué se predican todos estos atributos? Vilanova da diversas respuestas a esta pregunta. De acuerdo con él, el sentido común es una disposición peculiar a actuar de determinada manera, una propiedad de algunos hechos, un conjunto de dichos y pensamientos humanos, un sistema de conocimientos comunes sobre hechos comunes, un concepto que nació como una expresión (p. 199), un conglomerado de creencias y de normas de conducta compartidas por una comunidad, un tipo especial de discurso y así indefinidamente. Todo lo que Vilanova afirma puede ser cierto, pero nos quedamos en la misma oscuridad que en la que nos encontrábamos antes de leer su trabajo. ¿Cómo explicarnos este fracaso?

Lo primero que hay que señalar es que si hay algo que Vilanova no es, es ser un filósofo analítico. Vilanova no se toma la molestia de investigar los usos de las 
expresiones relevantes y por lo tanto se desentiende de la investigación conceptual en el sentido más estricto de la expresión. Llama la atención, por ejemplo, que en el capítulo sobre la memoria no se alude ni una vez a los verbos en pasado. Pudiera ser, por ejemplo, que 'sentido común' tuviera varias acepciones, es decir, que tuviéramos no una sino varias nociones de sentido común. Una hipótesis así, que Vilanova ni siquiera contempla, explicaría la variedad de sus atributos y por qué en algunos casos tendría sentido decir, e.g., que el sentido común es asistemático o explicativo y en otros no. En mi opinión uno de los más graves errores de Vilanova es haber identificado el sentido común con un sistema de creencias. Las creencias pueden ser de sentido común, pero es un error identificar el sentido común con un grupo de creencias, sean las que sean. Contrariamente a lo que Vilanova sostiene, inclusive en un contexto de debate científico especializado un científico puede hacer gala de sentido común al inclinarse por una teoría antes que por otra. ¿Por qué? Porque en su sentido fundamental, 'sentido común' apunta sobre todo a un facultad, asociada con el uso del lenguaje, que permite jerarquizar, priorizar, preferir, etc., acciones, pensamientos, decisiones y demás. La relación entre los conceptos de sentido común y lenguaje natural es uno de los factores fundamentales de los que Vilanova simplemente se desentendió, si bien sí intuye su relevancia. A mi modo de ver, el no haber examinado a fondo la relación entre el lenguaje natural y el sentido común es lo que nos da la clave de lo que en última instancia es un esfuerzo filosófico heroico, pero fallido.

El texto contiene diversas erratas y errores que sería conveniente corregir. No hay tal cosa como 'strictu sensu' sino 'stricto sensu', una manera no es naif sino (en todo caso) naive (con dos puntos sobre la 'i', para que la pronunciación sea la que conocemos), no se dice 'de motu propio' sino 'de motu proprio', no es 'éstasis' sino 'éxtasis', etc., además de ciertas oraciones mal construidas (e.g., "hemos hecho rápido tanto al origen...”, p. 207). Estas son, sin embargo, fallas menores que no le restan mérito al trabajo filosófico de Vilanova, pero que sería conveniente corregir para una segunda edición.

Yo pienso que el gran mérito de Javier Vilanova consiste en que logra abrirle al lector el apetito filosófico. Podemos estar en desacuerdo con su enfoque, su tratamiento y sus resultados, pero más allá de todo eso está la sensibilidad filosófica, la profundidad de un atisbo, el avance en comprensión logrado a base de un gran esfuerzo. Yo al menos no tengo la menor duda de que el libro de Vilanova contiene ideas valiosas y aprovechables. Pienso, por consiguiente, que se trata de un texto al cual hay que darle la bienvenida, así como a su autor le extendemos nuestro agradecimiento por alcanzar eso que no todos logran, a saber, hacer nacer en 
nosotros el deseo de reflexionar por cuenta propia sobre los apasionantes temas que él tuvo a bien poner a consideración de sus potenciales lectores.

Alejandro Tomasini Bassols Universidad Nacional Autónoma de México altoba52@gmail.com 